\title{
Operations research at CSIR: A brief history through cases
}

\author{
HW Ittmann* $\quad$ FE van Dyk ${ }^{\dagger} \quad$ IA Meyer $^{\ddagger} \quad$ SJJ van Rensburg ${ }^{\ddagger}$
}

Received: 24 October 2006; Revised: 7 December 2006; Accepted: 11 December 2006

\section{Dedication to Emeritus Professor Gerhard Geldenhuys}

There are few people in South Africa who have played a larger role in educating Operations Researchers than Gerhard Geldenhuys. He almost hand-picked those that he encouraged and guided through their Operations Research (OR) studies. Many of these researchers found their way to the OR group at CSIR where they all made a significant impact. CSIR honours not only a great educator, but also someone who was instrumental in the establishment of OR at CSIR. Prof Geldenhuys' influence within this organisation started almost 45 years ago and is still felt today. He was meticulous in his work, very modest as a human being and caring as a teacher.

\begin{abstract}
Apart from work in the mining industry during the 1950s, the first real Operations Research (OR) group in South Africa was established at CSIR in the early 1960s. Those initially involved in this group played a significant role in establishing OR at various universities in South Africa. The OR group at CSIR did, however, continue and today the group still exists. This paper presents a brief history of this group and endeavours to provide a glimpse of some of the projects conducted over the many years since its establishment.
\end{abstract}

Key words: History of OR, OR applications, case studies.

\section{Introduction}

The history of Operations Research (OR) and CSIR can be traced to the origins of the discipline during World War II. At the outbreak of the war Basil Schonland, professor of geophysics and director of the Bernard Price Institute at the University of the Witwatersrand, joined many other scientists to assist the allied forces. He became superintendent

*(Fellow of the Operations Research Society of South Africa) Corresponding author: Logistics and Quantitative Methods, CSIR Built Environment, PO Box 395, Pretoria, 0001, South Africa, email: hittmann@csir.co.za

${ }^{\dagger}$ Logistics and Quantitative Methods, CSIR Built Environment, PO Box 320, Stellenbosch, 7599, South Africa

${ }^{\ddagger}$ Logistics and Quantitative Methods, CSIR Built Environment, PO Box 395, Pretoria, 0001, South Africa 
of the British Army Operational Research Group and later scientific advisor to Field Marshal Montgomery [1]. At the end of the war, the then Prime Minister, General JC Smuts, recalled Schonland to South Africa to establish the Council for Scientific and Industrial Research (CSIR). CSIR was legally constituted on 5 October 1945 with the aim to "undertake certain types of research work; assist research work sponsored by others; and encourage the training of research workers, etc" [19].

In 1961, the National Research Institute for Mathematical Sciences (NRIMS) was established as part of CSIR and very soon the possibility of creating an OR group was being explored. In this regard, Geldenhuys $[10,11]$ played a significant role. He presented a series of lectures in which he covered a number of OR techniques, including linear programming, game theory, infinite games, queueing theory and dynamic programming. In addition, he compiled a comprehensive literature review on the applications of Operations Research. The report classified different problem applications into a number of areas. These included planning, trade and industry, agriculture, forestry and associated areas, local government, hospitals, postal services and transport, and defence.

OR has been practised and used within CSIR by various groups over the past almost 45 years. It is very noticeable that many of the areas that Geldenhuys identified were addressed in one way or another by these groups. In this paper, we endeavour to highlight a few of the OR applications conducted by CSIR since the inception of its OR group. Initially, a short overview is presented of OR at CSIR over the years.

\section{OR at CSIR}

The way in which OR has been practised at CSIR has been largely influenced by the strategic direction of the organisation. During the initial years, the work of the OR group at NRIMS was mainly focused on problems of a military nature. This was due to the fact that OR was already an accepted discipline within the military domain while funding was also available from the Defence Force for OR-related work. There were, to the best knowledge of the authors, one or two exceptions (see $\S 3$ ).

During the late 1960s and early 1970s, many OR departments were established at various universities across South Africa. Most of the original Operations Researchers at CSIR left to join these departments. The few that remained focused largely on defence work, although there were efforts to formalise theoretical OR research work [28] and to conduct non-military work. For example, as a result of the oil crisis in 1973, the CSIR group became very involved in energy-related work [42].

It is impossible to list and cover in a single paper all the different projects in which the OR group at CSIR was involved over the years, but some of these include:

- a transportation model and a sales forecasting model to assist in the location of new petrol stations for ENGEN,

- various distribution models for different private sector companies,

- an integrated operations control system for SAA with industry partners, 
- a simulation model for coal export as part of a feasibility study,

- a trackless mining simulation model,

- numerous simulation models in the rail environment,

- vehicle routing for beer distribution, and

- elections forecasting.

During the early 1980s, the landscape started changing within CSIR, with the entire character and nature of the organisation shifting from conducting research to becoming more market-oriented. A strong drive towards financial sustainability seriously impacted on the research nature of the organisation, affecting all the groups within the organisation.

One such group was the relatively strong and stable OR group within CSIR. The emphasis, for the OR group, was to solve complex problems for clients, for which the clients had to pay. The OR group, which had originated in NRIMS and remains intact until today, was able to survive this period through specialist consulting projects, typically of a shortterm nature. This environment with its constant pressure to deliver to clients was not conducive to research work, let alone the production of research papers! As a result, very little research was conducted, but many different problems from a wide spectrum of domains were addressed. Some of these are described in this paper.

\section{The Maize Board transportation problem (1962-1988)}

In his brief history of the beginnings of OR in South Africa, Geldenhuys [12] states: "One of the first major tasks of NRIMS was a large project for the South African Maize Board on the distribution of maize in the country, which could be described as a transportation problem in linear programming with the complication that the model was also expected to make pronouncements on the economic sustainability of mills."

This project was tackled by a team in 1962/63 and remained with CSIR for many years. The problem entailed the transportation of a commodity, maize in this case, between supply and demand points scattered throughout the country in such a way that total rail cost could be minimised.

This is an example of a classical transportation problem. There were approximately 300 different supply points (granaries, silos, etc.) and approximately 120 demand points (mainly mills and factories) scattered across the country. The aim of the Maize Board, the statutory body receiving all maize in South Africa, was to ensure that maize farmers received a fixed price for their maize, which would ultimately result in a reasonable profit. In addition, total transportation or rail costs needed to be minimised for delivery to all users. This was termed the "primary" optimisation problem.

Secondly, and this was also critical, a level of fairness to the users or demand points had to be ensured. The average costs paid per ton of maize had to be distributed fairly or equitably to the user points; for example, all demand points at the same location needed to pay the same average cost (price) per ton of maize supplied. Achieving this "fairness" was 
one of the major challenges of this problem. Merely solving the classical transportation problem, i.e. the linear programming problem, does not ensure this.

Solving the problem involved the following steps:

- determining shortest paths between all the supply and demand points,

- using these shortest paths to obtain rail costs from a rail tariff table supplied,

- solving the classical transportation problem to minimise total rail costs, and

- ensuring "fairness" amongst the various demand points.

Initially, achieving "fairness" was addressed using an intelligent heuristic to shift maize between points with the aim to eliminate non-fairness throughout the solution. However, there was a substantial redundancy in the basis of the optimal solution. This implied that one could search for - and find - a solution that would be the most equitable to the users.

Having struggled for many years to find an acceptable fair solution, Stewart and Ittmann [33] found an elegant way to address the issue of obtaining equitable solutions. In solving the primary problem, one has an optimal solution in the sense of minimal rail cost. Severe redundancy in this solution implied that there was no unique solution. The challenge was to find the most equitable solution amongst the many possible solutions. This was achieved by formulating the second stage of the problem as a goal programming problem. For each one of the demand points (users), an equitable or fair total cost was defined and calculated using a heuristic method. This cost was then considered to be the goal cost and the objective was to minimise the sum of the deviations (over- or under-achievements) from this goal for each one of the demand points. This approach achieved much better results. For the rest of the lifespan of this model, the Maize Board used this approach to run two solutions annually, one with the crop forecast and another with the actual crop.

The impact of the evolution of computer technology and how it influenced the attainment of a solution to this model was interesting. The model was originally developed using an IBM 704 computer. CSIR was the first organisation in South Africa to acquire an IBM 360 and the model was adapted to run on this "large" machine. Physically the IBM 360 was enormous and a box of a couple of hundred punchcards had to be read by a card reader to submit the model to the computer and obtain a solution. The model used the entire memory of the IBM 360 and expended, on average, 20 minutes CPU time to obtain a solution. This implied that the model could only be run overnight, a long and tedious task. The program was coded in FORTRAN. During the late 1980s, with the introduction of the personal computer (PC), the program was adapted to run on a PC at the Maize Board [39, 41]. It took a few seconds of CPU time to run this optimisation problem on the PC. After close to twenty five years, CSIR parted ways with the Maize Board transportation problem in 1988.

\section{OR for the military (1970-1985)}

The OR group was involved in many projects for the Defence Force, especially during the early years. These projects covered a wide spectrum of diverse problem areas. A few of 
the larger projects are highlighted in this section.

\subsection{War gaming}

War gaming was, and still is today, a very efficient and cost-effective way to expose the professional soldier to a real war environment. One of the initial larger projects the newly established OR group undertook for the Defence Force was to draft war gaming rules for the SA Army College war game [3]. Initially this was a "hand-driven" game: forms were filled in and calculators were used to perform computations. Only later, when cheaper computer possibilities became available in the 1980s, were the war games computerised.

The game was conducted between two opposing forces, namely a blue and a red force. In the early years the CSIR researchers were involved in the game, specifically in assisting the referees in running the game. The rules consisted of some general rules addressing aspects such as mobility, sighting, the passableness of terrain, etc. Various Defence Force unit types such as infantry, artillery, paratroops, armoured corps, armoured cars, antiaircraft, etc. were defined. There were also rules on how to combine these corps types into different fighting units. In executing the game, actual battles were very important and for these the fire-power of the different groups and units were defined up front and values were allocated for the different units. There were specific ways to calculate and evaluate the outcome of a battle and in this regard vulnerability was critical. Separate rules were established for logistics as well as air support. For many years these games were held using the rules developed by CSIR to calculate the outcomes of an engagement manually. All the different factors and rules were considered in these computations, and CSIR's operations researchers played an important role in supporting the referees in these calculations.

With the advancement and evolution of computers whereby these became smaller and more affordable, a major advancement was a project to computerise the war game rules [24]. The existing rules were literally used as is to computerise the war game, using a dedicated mini-computer that was purchased specifically for this purpose. Not only were the rules fully computerised, the CSIR team also wrote the operating system for this computer. The entire computer was therefore dedicated and oriented towards war gaming. The system was used for a number of war gaming exercises and was subsequently taken over by the SA Army.

\subsection{Long-term planning in the South African Air Force}

A management gaming model, or simulation, was developed for the South African Air Force (SAAF) to aid in its long-term planning [16, 17]. During the 1980s it was very important to identify the future requirements of the SAAF in order that the necessary steps could be taken to address any deficiencies. The model was developed as a tool to aid the SAAF in identifying possible future deficiencies and requirements. The tool simulated the evolution of the SAAF, taking into consideration aspects such as cash flows, the physical status of the SAAF, projects currently under way and the readiness of the SAAF to meet its tasks or threats. The tool was implemented as an interactive computer system and was possibly one of the first "decision support tools" used within the entire 
Defence Force. In parallel there were efforts to develop optimal strategies for the SAAF through a linear programming model [30].

\subsection{Simulation model to assess strike aircraft performance}

In 1979 the strike aircraft that formed part of the SAAF were reaching the end of their lifespan and it was necessary to identify replacements. A requirement was expressed to develop a tool that would assist in comparing different types of strike aircraft under operational conditions. The CSIR's OR group [32], in close collaboration with ARMSCOR, who expressed the need for such a tool, developed a simulation model for this purpose. This was a stand-alone simulation tool, developed in FORTRAN, that attempted to simulate a full operational situation as realistically as possible. Different threats were defined and a full squadron of the specific type of strike aircraft was deployed under operational conditions to eliminate the threats. Taking the characteristics of the aircraft type as well as different weaponry configurations into consideration, the simulation was initiated by sending continuous sorties of aircraft to attack these threats. At any stage on the way to the different targets the sorties of aircraft could be intercepted by enemy aircraft, come under attack of anti-aircraft defence systems or become unserviceable in flight and then had to return to base. At the target the attack was also simulated and the outcome of each attack was computed.

Different scenarios were simulated for each of the different strike aircraft types, and at the end the summarised results were compared. This provided useful information and an insight into the various options for ARMSCOR and the SAAF. As a result of the political situation that prevailed in the country at that stage, this exercise resulted in a decision to sanction a major upgrade of the entire fleet of strike aircraft that was at that time part of the SAAF.

\section{$5 \quad$ Simulating coal export channels for SASOL (1992/3)}

During the early 1990s, SASOL was positioning itself to export coal from Secunda via Richard's Bay harbour. This exercise would entail the overland movement of coal from opencast and underground mines at Secunda via conveyor belts to a beneficiation facility, and then via rail to the harbour [21].

As with any problem that ideally lends itself to solution by means of simulation, the proposed system was characterised by different variations along the channel. Coal was being produced at the mines at varying rates, and was of varying grades. On the demand side, the arrival of ships at the harbour was subject to variation in transport time, availability of berthing, as well as loading capacity and unloading rates. Along the channel, variations occurred as a result of breakdowns in conveying and processing equipment and, of course, variations in train arrival and transit times.

Insufficient availability of coal at the harbour would imply that berthing costs would be incurred. This potential loss could be catered for by the development of stockpiles along the line, which would require capital investment. However, excess coal in stockpiles along the chain could potentially lead to spontaneous combustion and loss of stock. The 
challenge for SASOL was to design a channel that had sufficient capacity to cope with the numerous variations along the chain so as to ensure availability of stock at the harbour, while at the same time not over-investing in stockpile capacity.

The challenge at the time was to develop a PC-based simulation model that could adequately reflect the flow of coal along conveyor belts (a continuous process), while at the same time dealing with discrete events such as the breakdown of equipment, ship arrivals and departures, and rail transport of discrete loads of coal. While this problem might be considered trivial given current technology, the PC-based simulation software at the time mostly catered for either discrete-event or continuous simulation problems, but rarely for both.

A simulation model was developed in SIMAN and CINEMA, which was predominantly rooted in a discrete-event design philosophy. Workarounds to accommodate the continuous nature of the flow of coal were developed using FORTRAN, and user interfaces were developed in Turbo Pascal. The model was used to assess the impact of different proposed channel configurations. Within a selected configuration, appropriate stockpile sizes were then determined for each of a number of proposed stockpiles along the channel.

\section{Trackless mining simulation (1993)}

The mining industry in South Africa has always been a fertile area for OR applications. Over the years the OR group at CSIR was involved in a number of studies in this sector. One of these involved the development of a simulation model of a trackless mining situation $[20]$.

This study was conducted in a specific shaft of a mine in the Witwatersrand area where trackless mining had been introduced. The personnel of the mine had gained extensive experience in trackless mining and were able to fine-tune operations to meet their immediate production goals. However, the selection and allocation of equipment seemed to be achieved in an ad hoc manner, according to experience. The number of units of a specific type that were utilised in the process had a definite effect on production. For example, if too few units were employed, certain processes might take too long, causing subsequent processes to be delayed. On the other hand, if too many units were employed the operation became congested causing under-utilisation of the expensive equipment. The capital and operating costs of trackless equipment are high, and a cost-effective fleet size had to be maintained in order to ensure cost-effective operations. The purpose of this project was to provide a means of assessing the impact of changes to the vehicle fleet size on production in a trackless environment. The focus was on the production and transport equipment.

Mining is to a large extent a transport operation, and effective transport mechanisms are essential to ensure cost-effective ore retrieval. In a trackless operation ore is transported from the face to a transfer point by means of a Load-Haul-Dump (LHD), where it is loaded onto dump trucks. A transfer point is a place where dump trucks are waiting to receive ore from LHDs, and each transfer point is positioned at an average distance of 50 metres from the face. Dump trucks transport ore from the transfer points to one of four tips. A tip consists of an opening in an ore pass, over which a number of steel bars are placed to 
form a grid through which the ore is forced. These ore passes are used to transfer ore to a lower level in the mine.

A discrete-event simulation model was developed to model all the mining operations in such a trackless environment. Although it was based on the operations of a specific mine, the model was flexible enough to be used and applied to any typical wide-reef trackless gold-mining operation. The model was developed using the simulation package SIMAN, and the system was animated using the CINEMA animation software. In addition, to simplify experimentation with the model, a user-interface was developed that allowed the user to change a number of parameters interactively. In essence, this was therefore a decision-support tool for mining analysts to assess the effect of different fleet sizes on production so as to ensure that cost-effective operations were conducted.

\section{A train scheduling model $(1995 / 6)$}

Freight and passengers are the main "commodities" transported by rail. The objective is generally to get the freight and passengers to their respective destinations in the quickest and most cost-effective way. Spoornet was investigating the possibility of introducing a "predictable service" for the transportation of freight where freight could be booked on a train with a guaranteed arrival time at its destination.

All trains do not travel at the same speed. Also, a large portion of the South African railway network consists of single tracks with loops that allow trains to pass each other. These could be trains travelling in opposite directions or in the same direction at different speeds. The schedules of different trains are therefore interdependent, which makes the scheduling of trains a complex problem. Spoornet approached CSIR to assist with the development of a train scheduling programme that would produce a viable train schedule [40]. At the time, the national train schedule was being developed manually.

During the development of the schedule, all the normal safety and operational "rules" had to be taken into account, e.g. whether it was a single or double track, the "occupation" of the track, the changing of locomotives and the length of the trains versus the length of train a station could accommodate. Aspects that were not considered included electricity usage, critical signals and a limit on the number of trains that could simultaneously be at a station. Because of the complexity of generating a train schedule for the whole Spoornet network, only the generation of a train schedule for a mainline section was investigated.

To construct the schedules, data were required on the number of stations on the track and the length of train that each station could accommodate, the number of trains and, for each train, the station of origin and the departure time, the destination station, the type of train (speed), the work-plan of the train (stopping stations) and the train length (stations where the train was allowed to stop). The problem was formulated as a network optimisation model with nodes for the stations and arcs for the time delays of activities such as travel time and the crossing of trains on single lines. The train schedule was generated by calculating the longest path for each train in the network. The train schedule program was developed in $\mathrm{C}++$. 


\section{OR in the South African Police Service (1998-2000)}

During the period 1998-2000 CSIR undertook a study for the South African Police Service (SAPS) entitled Crime Analysis and Decision Support in the South African Police Service: Enhancing Capability with the Aim of Preventing and Solving Crime. One of the key activities of the project was a pilot study in the Western Cape involving the optimal allocation of resources based on temporal and spatial crime data.

It is well known that SAPS is severely understaffed and experiences serious shortages of vehicles, other equipment and facilities in general. It is therefore important that the available resources should be deployed optimally. A specific need in this regard that was identified during discussions with SAPS Management Services in the Western Cape, was the scheduling and rostering of police personnel in the Community Service Centres (CSCs, previously known as charge offices) in accordance with the varying demand for policing during a 24-hour day and from day to day during the week. At that time no mathematical models were used for this purpose.

The CSC staff includes both the officers who work at the CSC (to deal with phone calls and people visiting the police station to report cases, have documents certified, etc.) and those who man the vehicles to attend to calls. There has to be a minimum of one person at the CSC and two people to man a vehicle. At the time they operated on two 12-hour shifts. A person worked two day shifts, then two night shifts, followed by four days off. There was always the same number of personnel on duty, independent of the time of day or the day of the week. This resulted in a very simple roster of four teams of which two teams were manning the day and night shifts and the other two being off duty. The roster followed an eight-day cycle, which meant that a person's off days moved along one day at a time - a very fair system. However, there were some disadvantages to the system:

- The manpower level did not vary with the workload.

- During handover from one shift to the next, there was some "dead" time during which vehicles and personnel were not available to attend to calls (e.g. vehicles had to be inspected, weapons handed out/returned, cases transferred, etc.). Criminals exploited these situations.

- Handover took place before the start of the shift, which meant that personnel worked at least half an hour overtime (on top of a twelve-hour shift).

- The shift length was not in line with the new Basic Conditions of Employment Act that would come into effect for the SAPS in May 2000.

According to Management Services many of the police stations had a shortage of personnel and vehicles early in the morning and on weekend evenings until after midnight. It would be useful to have more personnel on duty during these busy times and fewer during the quiet times. More, possibly overlapping, shifts per day would provide the ability to vary the number of personnel on duty. However, some officers were of the opinion that the number of shifts per day should be minimised since time was lost with every shift handover. Also, the personnel were in favour of their existing shift system, since they had four days off after 
having worked for four days. Based on what was considered to be practical shift lengths and structures, Management Services expressed an interest in comparing the 12-hour shift structure based on a fixed shift size (that is, always the same number of personnel on duty) with the following alternatives:

- 12-hour shifts with a variable shift size,

- 10-hour overlapping shifts with fixed and variable shift sizes, and

- 8-hour shifts with fixed and variable shift sizes.

Two models were developed to assist Management Services, namely a shift model [36] and a roster model [37]. The shift model determines how many personnel should start their shifts at which times of the day to match the demand for personnel as closely as possible. This was formulated as an integer goal program over a horizon of one week. Data were obtained from a number of station commissioners about the number of personnel required for each hour of each day of the week, according to the workload at their particular station. This was used for lack of better data.

Once the shift model was solved, a roster had to be designed to allocate the personnel to these shifts in a fair manner. The roster model was formulated as a binary goal programming problem. Since it quickly becomes very large as the number of personnel increases, the problem is solved in two phases. Like the shift model, the roster model is solved for a particular shift length. In phase one the roster is determined as if there were only one shift per day, i.e. the total number of personnel required to work during all the shifts on a particular day are assigned to that day. In the second phase the personnel working on a particular day are split into the various shifts such that the correct number of personnel work during each shift.

The roster model uses the results from the shift model as input, i.e. the number of personnel required during each shift for a week. In addition, the user must specify lower and upper bounds on the number of shifts a person must work per week, the average number of hours a person should work per week and the maximum number of consecutive shifts a person is allowed to work. The model then calculates the minimum number of personnel required to cover all the shifts and generates a roster for this number of personnel.

The models were implemented in Quattro Pro spreadsheet software using the built-in optimiser, since Management Services were already using Quattro Pro for planning purposes. As the built-in optimiser is limited to 200 variables, the models had to be solved for 3-hour and 4-hour time slots. An add-in solver would be required for models with smaller time slots.

The models were well received by Management Services, the station commissioners and other senior staff. However, resistance was experienced from CSC personnel. Any shift structure that matched the demand for personnel more closely would probably result in more, shorter shifts per person per week than with the 12-hour shift system. Although the total number of hours worked per person per week would be the same or fewer, the number of days off would be fewer. Also, due to the severe personnel shortage, there were 
not enough people to be allocated according to the shifts and rosters suggested by the models.

The software was then used to prepare a few alternative shift structures with their accompanying rosters for the Crime Prevention Unit (CPU) at one of the pilot police stations. One of the shift structures with its roster was used on a trial basis. A reduction in this station's priority crimes was reported, believed to be a result of the improved utilisation of personnel which was achieved with the new shift structure.

More recently, SAPS managed to appoint more personnel and subsequently implemented 8-hour shifts with a fixed shift size at the CSCs. This has resulted in renewed interest from Management Services in revisiting the models.

\section{OR in agriculture - the fresh fruit industry (2002-2004)}

Towards the end of 2002, a consortium consisting of CSIR, Stellenbosch University and Optimal Agricultural Business Systems (OABS) was commissioned to undertake a study for the South African fresh fruit export industry. The aim of the study was to enhance the competitiveness of this industry by:

- promoting effective and efficient logistics operating practices amongst all the roleplayers in the fresh fruit export supply chain, and

- analysing the logistics infrastructure capacity in order to make recommendations for its utilisation and the possible need for investment in infrastructure.

Since the study has been described in previous papers $[2,3,38]$ only a brief summary is provided here.

It is estimated that the "farm gate" ${ }^{1}$ value of all fruit production in South Africa is approximately R10 billion, of which $53 \%$ is attributable to deciduous fruit, $34 \%$ to citrus and $13 \%$ to subtropical fruit [8]. Although the fruit industry's contribution to the GDP is only $3 \%$ (of which $15 \%$ is attributable to primary fruit production), fresh fruit is the largest agricultural export product in terms of volume (in metric tonnes) [26]. The fruit industry is also a significant employer. In 2002, the deciduous and citrus sectors together employed some 200000 people directly, with many more dependant on the fruit industry.

The study focused on the role-players in the South African portion of the supply chain, which comprises producers, pack houses, cold stores, exporters, transporters, logistics service providers and shipping lines, as well as on the physical infrastructure utilised by these role-players, e.g. ports. Since the deregulation of the fruit industry in 1997, the number of exporters and the number of brands have grown exponentially. This, in combination with the growth in export volumes, increases the pressure on the infrastructure; for example, a pallet of a particular brand rather than a generic product required by a client.

\footnotetext{
${ }^{1}$ Value of produce calculated before any packaging or other value addition takes place.
} 
The study comprised four phases and covered a large variety of activities (see [38] for an overview). The following modelling components are of particular relevance within the project:

- Simulation models were developed for Fresh Produce Terminals in Cape Town and Durban to analyse the flow of produce through these terminals in detail. The Durban model is described in detail in a separate paper [2].

- A maximum flow optimisation model of the infrastructure network was developed to determine the maximum volume of produce that can be handled by certain sections of the network [23].

- An Excel model was developed to determine the then current and potential future utilisation of the various conventional and container terminals that load fruit for export [38].

These models were used to determine whether investment in logistics infrastructure would be required in the foreseeable future. All the models showed that there was no immediate need for investment in additional infrastructure other than at the container terminals, which were operating too close to capacity, resulting in congestion and delays. These needs had already been identified by the relevant parties and capacity expansion plans were in progress. The congestion and delays experienced at the conventional terminals in Durban during the peak citrus season were identified to be largely due to the inability of the cold stores and transport management system in the greater Durban area to provide the terminals with a continuous supply of the right fruit at the right time and not to insufficient capacity at the terminals, as was perceived by many producers and exporters. This problem may be addressed by upgrading some of the cold stores and investing in IT infrastructure and software, both for cold store management and transport management.

There has been considerable interest in the study and its findings, and enquiries are still regularly received from diverse sources. The response from the fruit industry and funding partners was favourable and they were satisfied that the aims of the study had been met. All the reports as well as the Excel model are available free of charge on the website of the Deciduous Fruit Producers Trust [5].

\section{Conclusion}

This paper contains a brief overview of some of the work conducted at CSIR over the past 45 years in the area of OR. It is by no means exhaustive and is also biased towards OR applications. In the early years of the OR group's existence, more fundamental research work was conducted, which is hardly mentioned in this paper. However, as Geldenhuys [11] has shown - and as this short history illustrates - OR has many possible applications in

a range of different problem areas. Many of these application possibilities were achieved by the OR group at CSIR.

As indicated, this brief history is not comprehensive as far as the CSIR involvement in Operations Research projects is concerned. The first column in Table 1 shows the 
application areas as identified by Geldenhuys [11]. In the next column, the application areas of the CSIR cases reported here are shown. The last column shows additional CSIR cases in the identified application areas, which were not discussed in this paper. Even in this instance the list is not complete. It is clear from Table 1 that, ever since the inception of OR at CSIR, there have been applications in all the areas as identified by Geldenhuys, except local government and postal services. In addition, certain other areas in which CSIR has been active have not been mentioned. Examples include manufacturing, energy, crime prevention (through one of the first major Innovation Fund projects), logistics and supply chain management.

\begin{tabular}{|c|c|c|}
\hline Application areas & CSIR cases reported here & CSIR cases not reported here \\
\hline Planning & - & {$[14],[15],[22],[25]$} \\
\hline Trade and industry & {$[20],[21]$} & {$[4],[9],[34],[35]$} \\
\hline $\begin{array}{l}\text { Agriculture, forestry and associated } \\
\text { areas }\end{array}$ & {$[2],[23],[33],[38],[39],[41]$} & {$[6],[7]$} \\
\hline $\begin{array}{l}\text { Local government, hospitals, postal } \\
\text { services and railways }\end{array}$ & {$[40]$} & {$[13],[18]$} \\
\hline Defence & {$[3],[16],[17],[24],[30],[32]$} & {$[27],[29],[31]$} \\
\hline
\end{tabular}

Table 1: Application areas of OR [11].

One may ask what the future holds for the OR group within the largest Research and Development organisation in South Africa. This is a difficult question to answer. What is clear, however, is that the current CSIR has embarked on a strategy where research, or the generation of new knowledge, will increasingly be required from the researchers in the organisation. In this regard the wheel has almost turned a full circle: the organisation is returning to its original mandate where the aim was to "undertake certain types of research work; assist research work sponsored by others; and encourage the training of research workers, etc" [19].

To undertake certain types of research in the field of OR will be difficult and will require not only substantial investment, but also time. Fundamental research into developing new algorithms and techniques demand dedicated researchers who immerse themselves in the field. The group will possibly have to attract such researchers or cultivate them from post-graduates leaving university. The research work sponsored by outside organisations will typically be more focused and applied, and here the OR group can already make a contribution. Examples included in this paper show that it has been, and can be, done. Training of research workers is currently receiving considerable attention and funding has been made available for this purpose. In the "old" CSIR, prior to the mid-1980s, the organisation was referred to as a "PhD factory". In essence the drive is to replicate this situation again.

However, there is one overriding necessity, namely financial sustainability. To achieve all the objectives mentioned above, any group within the organisation, including the OR group, will have to remain financially sustainable. This is a fine balancing act and will be a serious challenge for those within the OR group. 


\section{References}

[1] Austin B, 2001, Schonland: Scientist and soldier, Institute of Physics Publishing and Witwatersrand University Press, Johannesburg.

[2] Bekker J, Mostert M \& VAn Dyk FE, 2005, Simulation of fruit pallet movement in the port of Durban: A case study, ORiON, 21(1), pp. 63-75.

[3] Burger AP, Grobbelaar JW, Haller A, Hanekom DJT, Money AH \& PerOLD R, 1970, Reëls vir SA Leërkrygspel Merk I, CSIR Contract Report, W/70/294, Scientia, Pretoria.

[4] Clarke K, Currin DC \& Ittmann HW, 1990, A system for cutting components with efficient utilization of material, Triennial IFORS Conference, Athens, Greece.

[5] Deciduous Fruit Producers' Trust [Online], [Cited August 21 ${ }^{\text {st }}$, 2006], Available from http://www.dfpt.co.za/fruit $\% 201$ ogistics/fruit $\% 20$ logistics.htm

[6] Dell M, 1993, Tiger oats wheat allocation system conceptual model, CSIR INFOTEK Report, DIS-47, Pretoria.

[7] Dell M \& Stylianides TS, 2005, A description of the FOREST IQ optimisation module, CSIR Technical Report (Confidential), TR-2005/23, Pretoria.

[8] Department of Agriculture, 2004/5, Abstract of agricultural statistics, Directorate: Agricultural Information Services, Pretoria.

[9] Drewes AK, Sniedovich M, Currin DC \& Ittmann HW, 1988, Mobil: Phase 1 report distribution problem description and proposed model outline, CACDS Contract Report, CKOMP 88/24, Pretoria.

[10] Geldenhuys G, 1963, Notes on some important techniques of operations research, National Research Institute for Mathematical Sciences, CSIR, Pretoria.

[11] Geldenhuys G, 1963, Toepassings van ondernemingsanalise, National Research Institute for Mathematical Sciences, CSIR, Pretoria.

[12] Geldenhuys G, 1988, A brief history of the beginning of operations research in South Africa, [Online], [Cited August 21 ${ }^{\text {st }}$, 2006], Available from http:// www.orssa.org.za/wiki/pmwiki.php?n=AboutTheSociety.EarlyHistory

[13] Ittmann HW, 1984, Die rol van operasionele navorsing by die inbedryfstelling van hospitale, ORSSA Annual Conference, Vanderbijlpark.

[14] Ittmann HW \& CuRrin DC, 1984, An overview of the SA Breweries production planning system, NRIMS Contract Report, CWISK 39, Pretoria.

[15] ItTMAnN HW \& CURRIn DC, 1985, Multi-product allocation and distribution, ORiON, 1(2), pp. 70-82.

[16] Ittmann HW \& CurRin DC, 1985, Projek intoxicate - Gebruikershandleiding, NRIMS Contract Report, CWISK 50, Pretoria. 
[17] Ittmann HW, Currin DC \& Stewart TJ, 1982, Project intoxicate: Interactive management planning model, NRIMS Contract Report, CWISK 24, Pretoria.

[18] Ittmann HW, Walus Y \& Hamner L, 1997, Decision support systems in health care, Methods of Information in Medicine, 36(2), pp. 82-91.

[19] Kingwill DG, 1990, The CSIR: The first 40 years, CSIR, Pretoria.

[20] Meyer IA, 1993, Equipment fleet size analyses in a trackless room-and-pillar gold mining operation, MSc Thesis, University of Pretoria, Pretoria.

[21] Meyer IA \& Van Rensburg SJ Janse, 1993, Simulation model of Sasol coal export channel, Mikomtek Contract Report, Pretoria.

[22] Moorhouse I \& ItTmann HW, 1987, Modelling towards spatial efficiency in school planning, South African Geographical Journal, 69(2), pp. 139-156.

[23] Ortmann FG, Van Vuuren JH \& Van Dyk FE, 2006, Modelling the South African fruit export infrastructure: A case study, ORiON, 22(1), pp. 35-57.

[24] Roets PP, Ittmann HW, De Boer W, Fourie LW \& Nel J, 1976, Project SENING - Program documentation, CSIR Contract Report, CWISK 11, Pretoria.

[25] Schmitz P, Maritz J, Stylianides T, Elphinstone CD \& Morojele N, 2005, A methodology to address the facility location needs of the Department of Home Affairs (DHA), CSIR Contract Report, CR 2005/41.10, Pretoria.

[26] Statistics South Africa, 2002, Census of commercial agriculture, Report No. 11-02-01, Pretoria.

[27] Stewart TJ, 1975, SADF budgets, Project Arcade, NRIMS Serial No. W/75/31, Pretoria.

[28] Stewart TJ, 1978, Research and operations research, ORSSA Presidential Address, ORSSA Newsletter, May, pp. 15-20.

[29] Stewart TJ, 1978, SADF cash flows, Project Arcade, NRIMS Serial No. W/78/16, Pretoria.

[30] Stewart TJ, 1981, Project intoxicate: Linear programming model, NRIMS Contract Report, CWISK 23, Pretoria.

[31] Stewart TJ, 1982, A method for determining allowable levels of over-commitment authority, Project Arcade, NRIMS Serial No. W/82/28, Pretoria.

[32] Stewart TJ \& ItTmann HW, 1979, Computer model for comparing the operational effectiveness of strike aircraft, NRIMS Contract Report, CWISK 15, Pretoria.

[33] Stewart TJ \& ItTmann HW, 1979, Two-stage optimization in a transportation problem, Journal of the Operational Research Society, 30, pp. 897-904. 
[34] Stewart TJ \& ItTmann HW, 1981, Linear programming model for the purse-seine fishing industry - Final report, NRIMS Contract Report, CWISK 20, Pretoria.

[35] Stylianides TS, 1998, A model of clinker capacity expansion, European Journal of Operational Research, 110(2), pp. 215-222.

[36] VAn Dyk FE, 1999, Shift models for SAPS, Pretoria: Transportek, CSIR, Contract Report, CR-99/073, Pretoria.

[37] VAn Dyk FE, 1999, Roster model for SAPS, Pretoria: Transportek, CSIR, Contract Report, CR-99/074, Pretoria.

[38] Van Dyk FE \& Maspero E, 2004, An analysis of the South African fruit logistics infrastructure, ORiON, 20(1), pp. 55-72.

[39] Van Rensburg SJ Janse, 1989, Mielieraad Program op die PC, CSIR Internal Report, IKOM 89/9, Pretoria.

[40] Van Rensburg SJ Janse, 1995, Beskrywing van die ontwikkeling van 'n treinskeduleringsprogram, CSIR Report, DIS-C162, Pretoria.

[41] Van Rensburg SJ Janse \& Ittmann HW, 1988, Transportasie probleem van die mielieraad - Programhersiening, CSIR Contract Report, CKOMP 88/13, Pretoria.

[42] Vermeulen PJ, Cooper CJ \& Ittmann HW, 1994, Synthesis study for energy statistics, modelling and scenario development, Report for Department of Mineral and Energy Affairs, Pretoria. 